\title{
STUDENT AND FACULTY PERCEPTIONS OF ACADEMIC DISHONESTY IN ONLINE CLASSES
}

\author{
Karen Paullet, Robert Morris University, paullet@rmu.edu
}

\begin{abstract}
Due to the demand for distance learning, universities and colleges are offering more online classes to accommodate this growing trend. With this shift in education, it is important to understand the students' and faculty perceptions of what constitutes cheating and unethical behavior in online classes. This exploratory study of 457 undergraduate students and 75 faculty members will assess what methods students utilizing to complete course work and which of these methods is considered academically dishonest by faculty. This study seeks to understand the gaps that exist between faculty and students to help establish a clear set of guidelines of permissible techniques for completing coursework based upon faculty and student perceptions.
\end{abstract}

Keywords: Distance Learning, Online Learning, Academic Integrity, Unethical Behavior

\section{INTRODUCTION}

Instructors are frequently challenged with the prospects of student cheating in online classes. Students and instructors alike are tethered to their electronic devices in our twenty-four-seven world. Students are highly connected to their mobile devices for fear of missing a moment of connectivity to those whom they feel compelled to maintain an electronic relationship. Instructors in academia are no different and also wear the stigmata of an electronic chain. An instructional challenge in the virtual world of academia is the preservation of the integrity of the online educational environment. As online instructors we often have to come to terms in which we are supposed to "believe" in a student's honesty and integrity.

As universities have attempted to remain competitive by offering online courses, faculty struggle with implementing techniques to limit what external resources students use to complete their assignments. There is no doubt that distance learning has always seen this challenge and many question the level of academic dishonesty that occurs in these courses. As a result, universities and colleges should focus on implementing techniques and guidelines to mitigate the risk of academic dishonesty. This study seeks to understand the gaps that exist between faculty and students to help establish a clear set of guidelines of permissible techniques for completing coursework based upon faculty and student perceptions.

\section{BACKGROUND}

According to Howell, Sorensen \& Tippets (2010), distance educators are concerned about the integrity of their courses but few are willing to spend time or resources to continually learn the newest cheating methods and techniques for prevention in their online classes. A study conducted by Grijalva, Kerkvliet, and Nowell (2012), examined the level of cheating in online courses. The researchers used class cheating and testing policies to examine student responses. The findings revealed that academic dishonesty in a single online class is no more prevalent than in traditional classrooms. Throughout education, students have always come up with excuses as to why their assignments are late. A familiar reason is "the dog ate my homework." In 2020 student's excuses have changed. We now hear, "the dog ate my flashdrive," "the Internet connectivity dropped while I was taking an exam," or "I did not have a Wi-Fi signal”. Technology has provided students with new opportunities for academic dishonesty. Students can now search the Internet while taking an online exam, or use thoughts and references of published authors as 
their own during an exam or when completing assignments. The ease of cheating and plagiarism in online courses is less visible to their classmates and instructors.

\section{Dishonesty Methods Used by Online Students}

A 2017 study by Kessler International revealed that 86\% of students stated they cheated in some way online, 76\% copied material from somebody else's assignment and 79\% admitted to plagiarism from researching information online. Additionally, $72 \%$ stated that they used their mobile devices to cheat, $42 \%$ purchased custom term papers online and $28 \%$ had a service take their online classes for them (Burkett, 2017). It is not illegal for any of the above mentioned items, however; it is unethical.

Students are now using new methods to cheat online. Krask (2017) provides an example where a student starts an exam so that they are able to view all of the questions. The questions are then printed so that the student has time to search for the answers. After printing the questions, the student then disconnects from the Internet which will cause the exam to lock, which in turn does not permit the student to enter the exam to finish. After searching for answers, the student emails the instructor, often times providing a screen shot of the connection loss from the Internet, and requests for the exam to be reset (2017).

Howell et al. (2010) note that one method of cheating involves the use of "braindumps," which are actual online businesses that provide students with studying services and often guarantee passing scores. Some of these sites may even offer access to exam questions and homework solutions directly from the instructor versions of textbooks, as well as access to previously graded essays or assignments. Four of the most well-known braindump sites are Cramster, Koofers, Scribd and Course Hero which are considered tutoring sites where students can review past exams, assignments and projects used in their current courses. However, braindumps can pop up in a variety of places, or even for very specific schools or courses. One professor from Indiana State University found her test questions for sale on eBay (2014).

In 2020 the world has been faced with the COVID-19 pandemic. Universities across the country and world were forced to move students to online and distance learning. With the immediate need to move classes to online came a new need for students to find new ways to be dishonest. Proctorio is a platform dedicated to lifting individual achievement. The company markets themselves as "The World's First Learning Integrity Platform" (Proctorio, 2020). As of May 25, 2020, listed on the company’s website is a job posting for a "professional cheater".

New technologies that have become available in 2020 allow students to automatically paraphrase other people's work making it very hard for instructors to spot plagiarism. The company Spinbot is an example of this type of service. They "spin" or take a group of words from a text and rewrite it in a different manner (Heilweil 2020). Another new technique being used is for students to plug a paragraph of English text into Google Translate and have it translated into another language. After it is translated into another they language they then copy the text back into Google Translate and have it translated back into English which will give it a new version that looks completely different from the original.

A (2019) study conducted by Inside Higher Ed surveyed 2,000 college professors and 178 administrators in regard to cheating in online programs. Sixty percent of faculty members believe that academic fraud is more common in online courses than face-to-face.

\section{Preventative Measures}

Pencil and paper testing are fast becoming antiquated and displaced by the growing trend of testing inside an online environment. One of the first concerns in accessing any website is the security of the site and user verification. Usernames and passwords are used as a security verification process for accessing accounts online. Even though technology can provide students opportunities for academic dishonesty, it can also provide ways to monitor and control these opportunities (Hill, 2016). When designing an exam, instructors have the ability to use a lockdown browser. A lockdown browser, such as Respondus, will not allow students to search the Internet during the exam from the computer that they are using. This method can help eliminate cheating by making the students aware that searching for answers while taking the exam is unacceptable. The reality is that the lockdown browser can become 


\section{Issues in Information Systems}

Volume 21, Issue 3, pp. 327-333, 2020

inefficient very quick since many students use and own multiple devices such as a Smartphone or tablet which would enable them to search elsewhere.

One way to mitigate cheating in online courses is to use a variety of assessment techniques rather than using only high stakes exams. If instructors rely on a combination of interactive discussions, writing assignments, quizzes, and projects as well as online exams, it makes it more difficult for students to cheat (Hill, 2016). Incorporating more written assignments and interaction written discussions can also help to reduce cheating. Instructors can become familiar with their students' writing styles, giving them greater confidence in recognizing possible fraudulent behavior. Plagiarism detection software can also be used on all written content as well, so the instructor has an additional method of testing authenticity of written work (2016).

During exams, some institutions now ban all electronic devices. In addition, identification, including a photo ID or biometric scan is often now required for students taking examinations at some institutions. Some institutions are using a system called WebAssessor which is a secure online testing tool used to administer certification exams. WebAssessor uses proctors and web cams to ensure that students match their photo IDs and allows proctors to view a student's face, keyboard, and workspace remotely. In addition, WebAssessor uses software that recognizes students' typing styles, for example, their speed of typing and whether or not they pause between typing specific letters. If the proctor sees anything suspicious, he or she can stop the student's exam immediately (Salesforce, 2020).

Cabrera (2013) offers several suggestions reducing the temptation and likelihood for i“learning assessment activities, namely testing and homework activities.” Tips for testing include: Purposefully select assessment methods, use of question pools, randomize questions, set timers, and displaying questions one at a time He bases this assessment on findings from D. R. Krathwohl (2001) revision of Bloom's taxonomy. "Although it may be difficult to prevent entirely, faculty can implement steps to reduce its impact in the student learning assessment process for online courses” (2013).

Jortberg (2017) surveyed students at Sullivan University in Louisville and found that, given a choice, students would prefer to answer challenge questions in order to verify their identity before an exam rather than other identification methods such as mandatory use of a web cam, biometric scanners, signature recognition programs, or having to come to campus to take exams.

Cabrera (2013) suggests following a mix of objective and subjective questions. Objective measurements of understanding would involve the use of multiple choice questions, multiple answers, fill in the blank, and true / false responses. Conversely, a subjective approach would entail the use of short answers or essay questions. This subjective approach requires a greater understanding of the material. Obviously, the mixing of question types does not guarantee test questions and answers will not be shared, it could correlate in some respect to the final grade.

A tip suggested by Cabrera (2013) is to use question pools. Question pools are best used when there are a large amount of possible questions in selective categories such as true/false, multiple choice, and fill in the blank. The test administrator selects an appropriate amount of time for each question category which can vary from class to class or semester to semester. New questions can be added or old ones deleted at the inclination of the faculty member.

\section{RESEARCH METHODOLOGY}

This study examined faculty at two small mid-Atlantic Universities during the period of March to May 2019. The population chosen for this study was comprised of 451 faculty members at both universities. A total of 75 respondents completed the survey. Additionally, the study examined students at two small mid-Atlantic Universities during the month of April 2019. The population chosen for this study was comprised of undergraduate and graduate students enrolled in on-campus and online programs of study. Undergraduate students and graduate students were surveyed in order to gather data from students 18 years of age and older. A total of 457 student respondents and 75 faculty respondents completed the survey. The surveys were conducted using Survey Monkey, an online tool, to gather and organize data. The data was imported into SPSS for further analysis. The researcher used Chi-square 
with a statistical significance at the .05 margin of error with a 95\% confidence level. The study aimed to address the following research questions:

RQ1: What are the student's ethical perspectives in regard to academic dishonesty in online classes?

RQ2: What methods are faculty using to combat academic dishonesty in online classes?

The faculty survey instrument consisted of 15 closed-ended and two open ended questions for further understanding of participant responses and feedback about unethical student behavior in online classes. The first three questions focused on faculty demographics; which included gender, age, and associated department. Questions 4 and 5 asked if the faculty members have taught online and if so, how many classes they have taught. The majority of the remaining questions aimed to ask what authentication methods the faculty used in their online courses for student identities and their experiences with students' ethical behavior. The two open-ended questions looked to understand if there were other methods that the faculty members used for validating student identities in online courses and any additional comments they may have about the topic.

The student survey instrument consisted of 18 closed-ended questions and two open -ended questions for further understanding of participant comments and responses. The first three questions focused on student demographics; which included gender, age, and education level. Questions 4 through 18 asked students if they completed an online course, methods used for student validation, tools / external sources used to complete assignments and exams, their ethical opinion of utilizing external sources measured through 5 choices (Strongly Agree, Somewhat Agree, Neutral, Somewhat Disagree, Strongly Disagree), and their self-assessment of their own personal philosophy when completing online course work. The final two questions asked the students of methods they felt could be implemented in an effort to validate student identities and any additional comments they may have about the topic.

\section{RESULTS}

\section{Faculty}

RQ2: What methods are faculty using to combat academic dishonesty in online classes?

The survey identified six methods that faculty could use to authenticate student identities in online courses. Each participant was permitted to select as many answers that applied to their teaching methods. The most utilized methods included using Turnitin for assignments and independent coursework at 52.31\% and $44.62 \%$, respectively. None of the participants said they used keystroke recognition devices. These results can be reviewed in Table 1 .

Table 1: Methods Used by Faculty to Combat Academic Dishonesty

\begin{tabular}{|l|r|}
\hline Method Used & $\begin{array}{l}\% \text { of } \\
\text { Respondents }\end{array}$ \\
\hline Proctored Exam & $6.15 \%$ \\
\hline Webcam Proctor & $3.08 \%$ \\
\hline Keystroke Recognition Devices & $0.00 \%$ \\
\hline Independent Coursework & $44.62 \%$ \\
\hline Respondus Lockdown & $21.54 \%$ \\
\hline Turnitin & $52.31 \%$ \\
\hline
\end{tabular}

The researcher wanted to better understand what faculty members do to prevent online cheating and what their level of awareness was in relation to websites that aide students with unethical behavior in online courses. The results of 
these questions are found below. It was alarming to see that only $21.54 \%$ of faculty provides students with an academic integrity policy. Other interesting findings included that over $90 \%$ of faculty do not check to see if their exams are posted online. Additionally, $82.81 \%$ of faculty have caught students using other's work in their online classes.

Table 2: Faculty Preventative Measures Used to Reduce Online Cheating

\begin{tabular}{|c|c|c|c|c|c|c|c|c|c|}
\hline & $\begin{array}{l}\text { Integrity } \\
\text { Policy }\end{array}$ & $\begin{array}{l}\text { Use } \\
\text { Online } \\
\text { Services }\end{array}$ & $\begin{array}{l}\text { Same } \\
\text { Exams } \\
\text { Each } \\
\text { Semester }\end{array}$ & $\begin{array}{l}\text { Check } \\
\text { Online } \\
\text { Sites } \\
\text { for } \\
\text { Posted } \\
\text { Exams }\end{array}$ & $\begin{array}{l}\text { Require } \\
\text { Reading } \\
\text { Code of } \\
\text { Conduct }\end{array}$ & $\begin{array}{l}\text { Believe } \\
\text { Students } \\
\text { Cheat } \\
\text { More } \\
\text { Online }\end{array}$ & $\begin{array}{l}\text { Caught } \\
\text { Students } \\
\text { With } \\
\text { Other's } \\
\text { Work }\end{array}$ & $\begin{array}{l}\text { Students } \\
\text { With } \\
\text { Work } \\
\text { From } \\
\text { Prior } \\
\text { Class }\end{array}$ & $\begin{array}{l}\text { Using a } \\
\text { Proctor }\end{array}$ \\
\hline No & $78.46 \%$ & $60.00 \%$ & $81.54 \%$ & $90.77 \%$ & $47.62 \%$ & $41.54 \%$ & $17.19 \%$ & $60.00 \%$ & $89.06 \%$ \\
\hline Yes & $21.54 \%$ & $40.00 \%$ & $18.46 \%$ & $9.23 \%$ & $52.38 \%$ & $58.46 \%$ & 82.81\% & $40.00 \%$ & $10.94 \%$ \\
\hline
\end{tabular}

\section{Students}

RQ1: What are the student's ethical perspectives in regard to academic dishonesty in online classes?

To better understand students' ethical perspectives, each participant was asked if they felt it was ethical to use external resources when taking an online class. Approximately $20 \%$ at each university felt that using external resources when taking an online course was unethical and close to $35 \%$ combined from both universities felt it was ethical. It is important to note that the survey indicated a list of external resources including mobile devices, other individuals, internet searches, and copies of the exams. Additionally, students were asked about their ethical view of using external resources when taking online exams. Opposing their view of using external resources when taking online courses, approximately $61 \%$ of the students at each university felt using external resources when taking an online exam was unethical. Both universities had less than $25 \%$ of the respondents who felt that using external resources while taking an online exam was ethical. A breakdown of these results for both University A and University B can be seen in Table 3.

Table 3: Students Use of External Resources for Online Class and Exams

\begin{tabular}{|l|c|c|c|c|}
\hline & External Resources in Class & \multicolumn{2}{c|}{ External Resources for Exams } \\
\hline Strongly Agree & $7.55 \%$ & $12.96 \%$ & $26.65 \%$ & $27.77 \%$ \\
\hline Somewhat Agree & $11.64 \%$ & $9.26 \%$ & $27.90 \%$ & $25.93 \%$ \\
\hline Neutral & $17.92 \%$ & $31.48 \%$ & $26.96 \%$ & $22.22 \%$ \\
\hline Somewhat Disagree & $23.27 \%$ & $14.82 \%$ & $12.23 \%$ & $16.67 \%$ \\
\hline Strongly Disagree & $39.62 \%$ & $31.48 \%$ & $6.26 \%$ & $7.41 \%$ \\
\hline Total & $100.00 \%$ & $100.00 \%$ & $100.00 \%$ & $100.00 \%$ \\
\hline
\end{tabular}

Students were asked to gauge their level of ethics when comparing themselves to other students. At both universities, greater than $60 \%$ of the students felt they were either very ethical or average ethical in comparison to 


\section{Issues in Information Systems}

Volume 21, Issue 3, pp. 327-333, 2020

other students. University A reported a very small percentage of students who stated they were unethical in comparison to other students. Lastly, University A and University B students reported 29.69\% and 34.0\%, respectively, that they felt somewhat ethical in comparison to other students.

\section{DISCUSSION}

The researcher was a bit surprised by the results of the survey questions related to the faculty members' efforts to combat unethical online behavior. Only $21.54 \%$ of the respondents had students sign an academic integrity policy. Additionally $40 \%$ of the faculty found examples where students submitted work from other students in previous semesters. Of the respondents, only 9.23\% stated they reviewed online sites to see if copies of their exams and assignments were posted. Given the lack of familiarity with services available to students and the faculty feedback, the researcher concluded that with additional awareness, faculty may be more inclined to safeguard their courses against these unethical student acts.

The student survey focused on the students' perspectives of using external resources such as mobile devices and internet searches in their courses and online courses and exams. The results illustrated that the majority of students recognized that exams are meant to test what they have learned and using external resources would be unethical when taking an online exam. However, students felt using external resources when completing coursework outside of exams was acceptable and ethical.

It can be assumed that students are leveraging external resources to help enhance their knowledge on the covered topics. Given these two statistics, it would be recommended that faculty and administrators continue to improve online exams to help combat external resources being used or implement exams that would allow external resources but go past the simple definition / theory questions to test the students' abilities of applying the learned concepts. Lastly, it would also be recommended that courses incorporate external resources in their overall course rather than finding methods to exclude them. Many learn best by researching the topic outside of the course shell. Given that students find the use acceptable, we should embrace it and allow them to broaden their knowledge rather than restricting them to content solely in the course shell.

\section{CONCLUSION}

Academic integrity has long plagued the educator. From grade school neophytes to doctoral degree candidates the temptation to and the admission of using others work endures. It does not matter if one is plagiarizing another's work, using crib sheets, or using an ancillary electronic device to circumvent security protocols when completing exams or other assignments.

Universities have many options available to them from various sites that will help assess the level of originality in student papers to services that offer proctoring of exams to ensure student identities. Of course, each of these options comes at a cost that universities may not be willing to absorb given the economic stresses surrounding higher education. However, failure to take preventative measures will likely cause negative effects to the university's reputation along with a potential decrease in enrollment if the university is perceived of lesser quality to their competitors by not implementing authentication measures in the online classroom.

Mobile device ubiquity and its simplicity of use have brought the world to the students' fingertips. Information, be it right or wrong, is only a click or two away. It is no small wonder that students are tempted to claim another's work or ideas as their own. These facts can lead faculty and administrators down one of two paths. They must either find better ways to restrict the use of external resources or embrace its use and find creative ways to enhance the course. Like the old saying "if you can't beat them, join them," this is a prime opportunity for universities to enrich their online courses past simple postings of PowerPoints and exams and implement interactive course material that drives and motivates students to go beyond the course content and truly gain an in-depth knowledge of the course materials. 


\section{REFERENCES}

Burkett, R.W. (2017). Kessler International new academic dishonest survey. Retrieved from https://tipsforfaculty.com/2017/03/03/kessler-internationals-new-academic-dishonesty-survey/

Cabrera, D. (2013, March). Tips to reduce the impact of cheating in online assessment. Northern Illinois University Instructional Design Center. Retrieved from http://facdevblog.niu.edu/onlinecheating

Heilweil, R. (2020). Paranoia about cheating is making online education terrible for everyone. Vox, Retrieved from https://www.vox.com/recode/2020/5/4/21241062/schools-cheating-proctorio-artificial-intelligence

Grijalva, T., Kerkvliet, J., \& Nowell, C. (2002) Academic dishonesty and online courses. Retrieved from http://oregonstate.edu/dept/econ/pdf/cheat.online.pap6.pdf

Hill, C. (2016). Student authentication: What are your duties under the HEA reauthorization? Faculty Focus Special Report: Promoting Academic Integrity in Online Education 4-7.

Howell, S., Sorenson, D., \& Tippets, H. (2016). The news about cheating for distance educators. Faculty Focus Specialty Report: Promoting Academic Integrity in Online Education.

Jaschik, S., \& Lederman, D. (2019). Faculty attitudes on technology A study by inside Higher Ed and Gallup. Inside Higher Ed.

Jortbert, M. (2017). Experiencing verifying the identity of distance learning students. $26^{\text {th }}$ Annual Conference on Distance Learning. pp. 1-5

Krask, A.M. (2007). Curbing academic dishonesty in online classes. TCC 2007 Proceedings. Retrieved from http://etec.hawaii.edu/proceedings/2007.krsak.pdf

Krathwohl, D.R. (2001). A revision of Bloom's taxonomy. An overview in L.W. Anderson and D.W. Krathwohl Eds. A taxonomy for learning, teaching and assessing. A revision of Blooms Taxonomy of Educational Objectives, New York. Longman

Proctorio. (2020). The world's first learning integrity platform. Retrieved from https://proctorio.com/about

Salesforce. (2020). Webassessor for partners. Education. Retrieved from https://partners.salesforce.com/s/education/general/Webassessor_for_Partner 